\title{
An empirical examination of customer advocacy influenced by engagement behaviour and predispositions of FinTech
}

\section{customers in India [version 1; peer review: 1 approved, 1 approved with reservations]}

\author{
Archana Nayak Kini (D), Savitha Basri \\ Manipal Institute of Management, Manipal Academy of Higher Education, Manipal, Karnataka, 576104, India
}

V1 First published: 11 Jan 2022, 11:27

https://doi.org/10.12688/f1000research.74928.1

Latest published: 23 May 2022, 11:27

https://doi.org/10.12688/f1000research.74928.2

\section{Abstract}

Background: The extensive adoption and usage of emerging technologies furthered by the global coronavirus disease 2019 (COVID-19) pandemic, has reduced direct face to face communications. New FinTech (financial technology) apps and technologies are flooding the Indian digital payments market and competitors are striving hard to attract and retain their customers. Especially when customer engagement behaviours (CEBs) are digital in nature, it is essential to gauge the intrinsically driven customer motivations which drive a positive CEB. The objective of this paper was to empirically test the influence of customer-based antecedents such as emotions, moral identity, self-concept, communal focus, perceived cost and perceived benefits on non-transactional experiential customer engagement behaviours (CEBs) and CEB's effect on customer advocacy in the FinTech industry.

Methods: Data from 380 financial app users in south India were gathered by administering a survey that captured customer predispositions, CEBs, and customer advocacy. Structural equation modelling (SEM) using smart PLS (partial least squares) 3.0 was applied to test the theoretical model.

Results: Results indicate that CEB fully mediates the relationship between self-concept and customer advocacy. The positive CEBs get formed through customer predispositions leading to referral/advocacy behaviours.

Conclusions: This paper provides directions for FinTech practitioners, marketers, technologists, and academicians to devise marketing strategies customized to customer needs and factors. This is one of the first research studies to demonstrate and empirically validate the CEB model for the FinTech industry during the COVID-19 pandemic.

\section{Open Peer Review \\ Approval Status \\ 1 \\ 2 \\ version 2 \\ (revision) \\ 23 May 2022 \\ version 1 \\ 11 Jan 2022

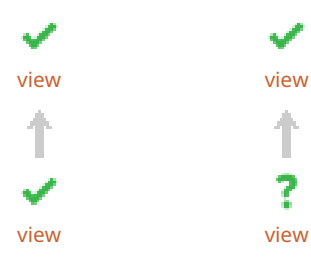 \\ 1. Naveen Kumar K (D), National Institute of \\ Bank Management, Pune, India \\ 2. Prashant Kumar, Asian Institute of \\ Technology, Pathumthani, Thailand \\ Any reports and responses or comments on the article can be found at the end of the article.}




\section{Keywords}

customer engagement behaviour, customer advocacy, e-word-ofmouth, emotions, perceived benefits, self-concept, FinTech, technology enabled services

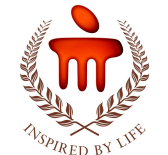

This article is included in the Manipal Academy

of Higher Education gateway.

Corresponding author: Savitha Basri (bsbasri@gmail.com)

Author roles: Nayak Kini A: Data Curation, Formal Analysis, Methodology, Writing - Original Draft Preparation; Basri S:

Conceptualization, Investigation, Project Administration, Supervision, Validation, Writing - Review \& Editing

Competing interests: No competing interests were disclosed.

Grant information: The author(s) declared that no grants were involved in supporting this work.

Copyright: @ 2022 Nayak Kini A and Basri S. This is an open access article distributed under the terms of the Creative Commons Attribution License, which permits unrestricted use, distribution, and reproduction in any medium, provided the original work is properly cited.

How to cite this article: Nayak Kini A and Basri S. An empirical examination of customer advocacy influenced by engagement behaviour and predispositions of FinTech customers in India [version 1; peer review: 1 approved, 1 approved with reservations] F1000Research 2022, 11:27 https://doi.org/10.12688/f1000research.74928.1

First published: 11 Jan 2022, 11:27 https://doi.org/10.12688/f1000research.74928.1 


\section{Introduction}

Since the liberalization of the financial services industry in India in the 1990s and the global financial crisis in 2008, the financial sector has undergone a series of changes and reforms. In India, the passage of the information technology (IT) Act of 2000 provided much-needed momentum to financial technology (FinTech) operations by establishing legal validity. With increased internet usage, the reduction of entry hurdles, and the easing of regulations, the post-crisis period from 2010 saw a tremendous rise in the use of financial technology (Feyen et al., 2021). FinTech firms provide financial services on digital platforms by combining innovative business models and advanced technologies such as artificial intelligence (AI), social media, data analytics and robotics acting as enablers. FinTech is setting a new paradigm in the design and delivery of financial products and services through alternative channels (Lee \& Shin, 2018). The key service offerings emerging on digital platforms in India include peer-to-peer (P2P) lending services such as Lendbox, Shiksha Financial, payment services such as Google pay, PhonePe, Paytm, BHIM, personal advisory services such as FundsIndia. com, Scripbox, PolicyBazaar, and BankBazaar, among others (Cyrill, 2018). India's digital payment is predicted to comprise $2.2 \%$ of the world's payments which is poised to reach $\$ 12.4$ trillion in another 3 to 5 years (Payments Council of India and PWC Report, 2020). The coronavirus disease 2019 (COVID-19) pandemic has ushered in a new era of contactless mobile banking. Retail payments in India through various digital channels rose from $\$ 37.7$ billion in financial year (FY) 2018-19 to \$48.35 billion in FY 2020-21 (1 US\$ = Rs 74.25, 03 August 2021) and mobile phone usage for banking operations in India grew from $61 \%$ in 2017 to $87 \%$ in 2021 (RBI, 2021). India along with China accounts for the highest FinTech adoption rate of $87 \%$ compared to the global adoption rate which is at $64 \%$ (Ernst \& Young, 2017). An increase in the adoption of FinTech solutions was due to the COVID-19 pandemic. In emerging and developing markets such as India, FinTech has helped expand access to affordable financial services to the common masses in times of lockdown and social distancing (RBI, 2021).

FinTech is prompting drastic changes in the way financial transactions - especially payments and advisory services - are perceived, marketed and consumed (Mention, 2021). The most significant result of FinTech is that it has shifted the focus on customer's convenience and needs with anytime, anywhere banking, breaking down the time and distance barriers that traditional banking imposes. Consumers are also finding it easier to browse around and switch service providers in search of more product options, greater features, lower prices, or discounts. Customers, on the other hand, are perplexed because the market is swamped with services and products from a variety of providers. Additionally, unlike traditional banking techniques, FinTech is perceived as sophisticated and thus difficult to use by older cohorts who are not techsavvy. As a result, it has become incredibly challenging for FinTech firms to manage consumer demands, establish or retain a customer base, and hence obtain a competitive advantage.

Can gaining a certain level of customer advocacy help FinTech firms beat the competition in this emerging and dynamic market? Can customers be motivated to interact positively with other customers by nurturing their self-concept, emotional states of mind and pre-dispositions? Also, can achieving a certain level of engagement with the FinTech brand ensure customers endorse the products and services and become its advocates? It has been observed over the years that a services firm can gain a competitive advantage by retaining, sustaining and nurturing its customer base (Anderson et al., 2004) by looking beyond the repurchase behaviour. Digital and social media with their richer media not only help firms to connect but also communicate information and emotions to their immediate customers and also between customers (Sashi, 2012). Hence customer-to-customer (C2C) interactions help companies promote brand advocacy by listening and learning about customers' needs, influencing them through social media 'thought leaders' and also considering customer opinions (Constantinides \& Fountain, 2008).

Customization, personalization efforts, and systems that engage with customers are known to affect favourable e-WOM (e-word of mouth), reviews and testimonials. To personalise, it is useful to know consumers' channel preferences, breadth of engagement, time, effort, and money spent, as well as the kind of activities they engage in. These can then predict the intensity of their referrals and product reuse (van Doorn et al., 2010). In a COVID-19 world, where all these engagement behaviours are digital, interactive, brand centred and non-transactional, it becomes essential to gauge the intrinsically driven customer motivations. Customers' helping behaviour where they guide other customers with useful suggestions or solve a problem, or customers' sense of community could aid them in engaging with the brand. The emotions of happiness, anger, contentment, or disgust can motivate a desirable or an undesirable customer engagement behaviour (CEB) or a referral, working as a differentiator amidst competition. Establishing emotional connections with customers can build trust and in turn assist these firms to face several challenges and intense competition in the FinTech industry.

The goal of this quantitative study is to empirically test the conceptual model on the influence of customer-based predispositions on non-transactional CEBs, and its strength in predicting the resultant advocacy behaviours in the emerging FinTech industry especially in covid pandemic times. The study sample were FinTech app customers who use Google Pay, PhonePe and so on for payment services and BankBazaar, PolicyBazaar for advisory services. The results of 
this study may guide marketing managers to formulate robust segmentation, positional strategies in line with the emotional, self-concept and individual needs so that they engage positively with the brand. Customer engagement and advocacy behaviours gained from these campaigns can help the companies to build and retain the competitive edge in the market.

\section{Literature review}

Service-Dominant (SD) logic in the light of relationship marketing theory attempts to know the significance of customerto-customer $(\mathrm{C} 2 \mathrm{C})$ relational and referral behaviours in developing and maintaining loyalty and advocacy. The customer engagement framework in this study endorses Oliver's (1999) theory elaborating the belief-attitude-behaviour formation. In addition, social exchange theory (SET) proposes that customers display positive thoughts, feelings or behaviours towards a product or brand in reciprocation to specific benefits from the brand (Blau, 1964). CEBs arising through these processes help in spreading positive word-of-mouth (Oliver, 1999), thus advancing the underlying theories and also inspiring a future research agenda in this direction.

In a technology-intensive financial services sector, the use of new information and technologies has led to a reduction in direct physical contact with the customer. The online customer communities facilitate customers to have an open dialogue to understand and solve their problems mutually, thus effectively engaging with the brand community. This has changed the traditional roles of a buyer and a seller in such exchange relationships. Thus, customers create and share content and thus intangibly advocate the product and service value to other customers, influencing their purchase decisions. Customer advocacy is a natural side-effect of the forces that create a strong service provider-customer relationship and is a dominant pointer of repeat buying (Fullerton, 2011). An investment in the brand from an experiential approach consisting of CEBs determines customer advocacy (van Doorn et al., 2010; Moliner et al., 2018).

CEB denotes firm or brand centred behaviours that go beyond transactions but have positive or negative manifestations depending on the motivational drivers of the customer and are measured by valence (positive or negative), form $/$ modality, scope (temporal and geographic), choice of channel and customer goals (van Doorn et al., 2010). The form/modality component depicts ways in which customers express their engagement based on time and money resources available at their disposal. The scope encompasses customers' extra-role behaviours such as providing product-related feedback helping the company improve the product or develop new products (van Doorn et al., 2010; Kumar \& Pansari, 2016). Customers' social media influence (CSMI) embodies C2C conversations over social media channels sharing their views on product benefits, thus influencing other customers of the brand community positively (Kumar \& Pansari, 2016). Customers' choice of the channel such as communication via phone, in-person, in a retail setting or via the internet (email/ website) can impact the CEB in terms of immediacy, intensity, length and breadth of CEB (van Doorn et al., 2010). CEBs are those non-purchase $\mathrm{C} 2 \mathrm{C}$ behaviours where the customers influence the development of the firm's offering, brand identity through knowledge, skills, opinions, recommendations, online reviews and referrals on their own accord making it a part of experiential marketing (Jaakkola \& Alexander, 2014). Studies show that customer dialogue and engagement mediates the relation between emotionally connected satisfied customers and advocacy behaviours (Moliner-Tina et al., 2019). As per Figure 1, CEB is a mediator and it is primarily motivated by customers' pre-dispositions and which can predict customer behaviour defined by referrals and advocacy.

H1: There is a relationship between customer engagement behaviour (CEB) and customer advocacy.

Customer predispositions are the customer-based factors, mainly the individual traits and predispositions of customers which influence the product, brand decisions and CEBs (van Doorn et al., 2010). Levy and Hino (2016) and Bhat and Darzi (2016) substantiated that emotional and relational elements influence a bank's relation with customers rather than a purely transactional approach leading to bank advocacy. It was discovered that emotional states such as anger, regret, disgust towards the company or the brand can result in CEBs and customers' accumulated emotional experiences turning into actions and behaviours (Bagozzi et al., 1999; Martin et al., 2008) and positive emotions generate positive CEBs and vice versa. Emotional connections with customers help in exhibiting the desirable CEB working as a differentiator amidst competition (Garg et al., 2005; Levy \& Hino, 2016). A quantitative study observed that the emotional dimension of engagement has a positive effect on advocacy intention as well as the intention to reuse mobile payment services compared to the cognitive dimension of engagement which only influences advocacy intention (Glavee-Geo et al., 2019).

H2: There is a relationship between emotions and CEB.

H3: There is a relationship between emotions and customer advocacy.

Self-concept is defined as a "desire for positive recognition by others". Moral identity is similar to self-identity and manifests in helping behaviour. The greater the moral identity of a customer, the more is the engagement behaviour with the brand and more likely is the helping behaviour. Customers who displayed a higher value for self-concept tend to warn other customers from negative product experiences or recommend installing the right application thus exhibiting a high 


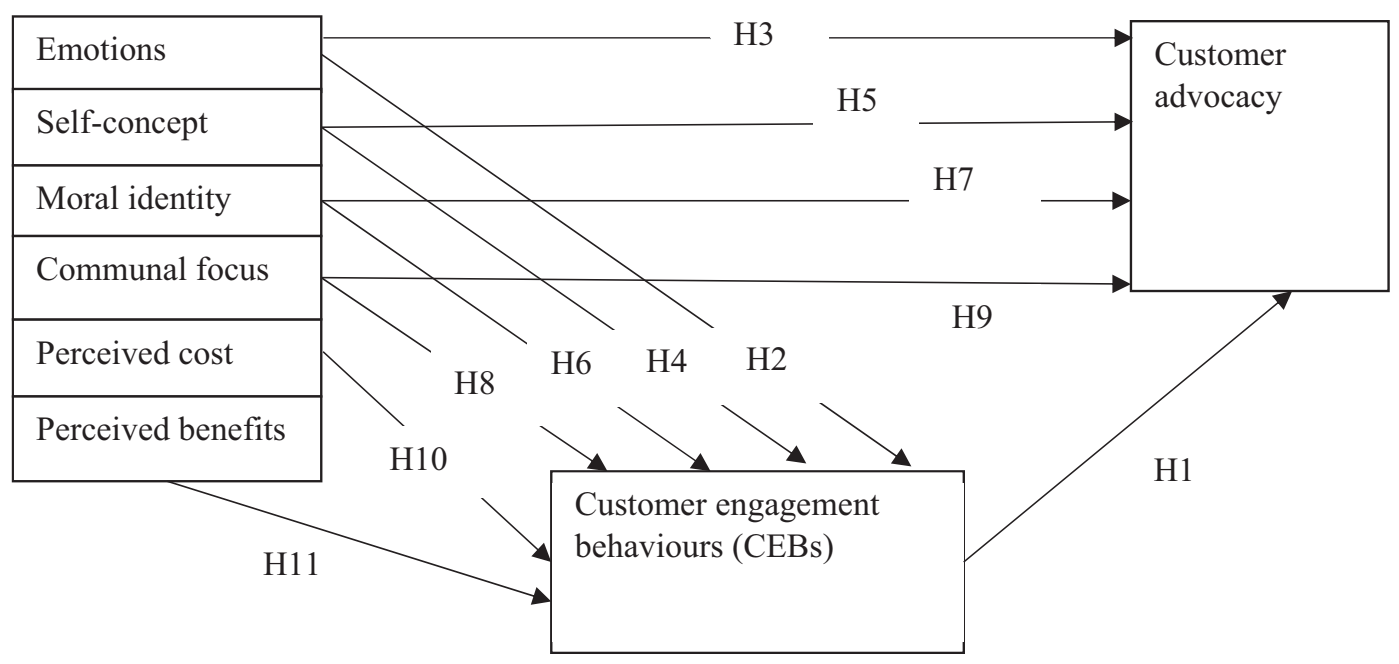

Figure 1. Theoretical model.

degree of CEBs (Hennig-Thurau et al. 2004). Similarly, customers with helping behaviour tend to participate in blogging or co-promote the brand with which they are involved (Sundaram et al. 1998). Customers who are emotionally linked to brands symbolizing their self-concept are more inclined to champion the brand and disseminate favourable information about the product. They are thus less likely to be lured by competitors, are less difficult to persuade to stay, and are more eager to recommend the product (Grisaffe \& Nguyen, 2011; Jayasimha \& Billore, 2016).

H4: There is a relationship between self-concept and CEB.

H5: There is a relationship between self-concept and customer advocacy.

H6: There is a relationship between moral identity and CEB.

H7: There is a relationship between moral identity and customer advocacy.

Communal focus is the behaviour where the people belonging to a particular community are likely to voice their support for their community during difficult times (He et al., 2008). It was revealed that a strong agentic focus is likely to be displayed by the female gender while they voice their negative WOM or advocacy. The motivations for involving in positive e-WOM may vary from the impulses which drive a negative e-WOM as evident in communal focus (van Doorn et al., 2010).

H8: There is a relationship between communal focus and CEB.

H9: There is a relationship between communal focus and customer advocacy.

Perceived cost and benefits are the perception by the customer related to the time, effort and money involved in buying and recommending the brand or product vis-à-vis the returns sought. Based on the perceived benefits and cost of engagement, the customer may engage in specific behaviours such as blogging or participation in online discussion forums or making donations to brand-related charity which has been defined as the form and modality of engagement (van Doorn et al., 2010).

H10: There is a relationship between perceived cost and CEB.

H11: There is a relationship between perceived benefits and CEB.

\section{Methods}

Ethical considerations

Written informed consent was obtained from all survey participants before administering the survey questionnaire. The content of the form started with the information sheet introducing the research objectives, its outcomes and implications before getting respondents' informed written consent. It contains statements on confirming that the data collected would be used for research and publication purposes keeping any personal details confidential (see Extended data, (Nayak Kini \& Basri, 2021c)). In addition, approval from the Manipal Institute of Management ethics committee was received for this empirical study in the Indian Fintech industry. 


\section{Research design}

Positivism philosophy was adopted for this study which helps to inquire the customers' emotions, attitudes and actions related to their app engagement scientifically and objectively. A cross-section of app users were initially chosen for the survey using a convenience sampling method and later this initial sample of app users helped to snowball their contacts who became the next set of respondents. The prevailing theories of engagement and exchange acted as a basis to understand the different phenomenon assisting in deductively formulating the various hypotheses to be tested for the theoretical model.

\section{Measurement tools/scales}

The survey questionnaire used a 5-point Likert scale adapted from several researchers such as Levy and Hino (2016) to capture customers' overall perceptions about self-concept, van Doorn et al. (2010) for communal focus, Hennig-Thurau et al. (2004) for moral identity, Hayashi and Bradford (2014) for perceived cost and Moliner et al. (2018), Kumar and Pansari (2016), for CEBs, and Moliner et al. (2018) and Han et al. (2008) for advocacy concerning the specific apps they were using. For emotions, a 7-point Likert scale was used which was adapted from Wong (2004). The survey can be found as Extended data (Nayak Kini \& Basri, 2021b).

\section{Data collection}

The universe for the study sample comprised of the customers of major FinTech payment and advisory applications such as Google Pay, PhonePe, Amazon Pay, BHIM, PayTM, BankBazaar, Policy Bazaar, and others in Karnataka located in southern region of South India. A pilot pretest with 38 respondents was conducted before administering the survey to a larger sample size during November 2020 and March 2021. A pilot pre-test is a trial run conducted before the final run for administering the survey. The pilot pretest conducted helps to identify any problems which might be encountered during the administration of the survey for data collection and find possible solutions before proceeding for the final study. The pre-test tried to gauge certain research design issues such as whether the respondents clearly understood the wording of the questions and also the time taken by the respondent to answer the whole questionnaire. The size of the sample for the pilot study was taken to be $10 \%$ of the sample size for the final study with sample size calculated to be 380 (formula below). The participants of the pilot test were chosen based on convenience sampling strategy but the initial criteria were that they had to belong to a city in Karnataka and also be using any of the above financial apps. We found out from the study that few questions and wording were hard for the respondents to understand, hence this helped to simplify the wording of few questions for the final study.

We had an initial contact list of participants chosen in the same way as that of the pilot study. These respondents were sent an unsolicited email introducing them to the survey and asking for their written consent. Once they provided the consent, the online survey link was shared with them and at the end of the survey, they were also asked to refer their contacts who used any of the FinTech apps. Thus, they helped refer their contacts' email ids as well as the phone numbers. This new group of people referred more people from their network with a snowball effect. This process was iterated until the final targeted sample size of 420 was reached. Response bias occurs when individuals respond to a survey leading to misrepresentation of their true value due to reasons such as social desirability and a set pattern of questions while filling. Response bias can also develop when the researcher's intent and the respondent's comprehension are not in sync. By using reversely coded, neutrally phrased, and brief questions, as well as avoiding leading questions, response bias was avoided.

Because the data was collected using a single survey instrument, there was a chance that common method variance (CMV) would occur (Podsakoff and Organ, 1986). Harmon's single-factor test was carried out in the software IBM SPSS 26.0 to assess CMV. From the exploratory factor analysis of the data related to CEB, four components such as form/ modality, scope, customers' social media influence (CSMI) and the choice of channel, emerged which together define the CEB. Thus CEB became the formative second-order construct formed by the four reflective first-order constructs which were validated by literature review.

\section{Sample size}

In terms of digital payments, Karnataka had the greatest adoption rate (26.64\%), followed by Maharashtra (15.92\%), and Delhi NCR (13\%). Hence, Karnataka was picked as the geographical area based on this information. The tentative final sample size was calculated to be 382 customers using the formula:

$$
\mathrm{N}=\left(\mathrm{z}^{2} * \mathrm{p} * \mathrm{q} \cdot \mathrm{N}_{\mathrm{U}}\right) /\left(\mathrm{e}^{2}\left(\mathrm{~N}_{\mathrm{U}}-1\right)+\mathrm{z}^{2} * \mathrm{p} * \mathrm{q}\right)
$$

where $\mathrm{p}=$ Proportion of defectives in the universe (Based on the pilot study, a $2 \%$ defect is assumed); $\mathrm{q}=(1-\mathrm{p}) ; \mathrm{z}=1.96$ (as per table of scores in a normal distribution within a selected range of $\mathrm{z}$ for a confidence level of $95 \%$ ); $\mathrm{e}=$ Acceptable error (an error of $2 \%$ of the true value is assumed); $\mathrm{N}_{\mathrm{U}}=$ Size of Universe.

After adding $10 \%$ to the calculated sample size to accommodate non-response errors, the target sample size was 420. 
Data analysis

The sample was measured for sample adequacy using the KMO test and Bartlett's Test of Sphericity using IBM SPSS 26.0. A principal component analysis was conducted to ascertain patterns in data and to condense the variables to a more manageable level. Based on the criterion of Kaiser (1960), all factors with eigenvalues 1 or greater than 1 were retained. It was observed that KMO values for all constructs involved in this model were $\geq 0.5$ (Cerny \& Kaizer, 1977) indicating that factor analysis is an appropriate method for further data analysis. Structural equation modelling (SEM) stating the path model and estimation of various quality parameters was analysed and reported using the Smart PLS 3.00 software, abiding by the latest guiding principles on Partial Least Squares (Hair et al., 2013; Henseler et al., 2012). First, the measurement model was evaluated to check the reliability and validity of various constructs. Smart PLS 3.0 software was used to validate and analyze this hierarchical reflective-formative model of CEB through the disjoint two-stage approach. The relevance of the hypothesised associations between the constructs was then determined using the structural model. Alternatively, JASP which is an open-source PLS 3 software can be used to undertake SEM using lavaan R package based on a covariance-based approach.

\section{Results}

Out of the 420 responses, it was found that 25 responses had incomplete responses and 15 other responses had a straightlining pattern, hence 40 responses were discarded and 380 responses remained to be analysed (Nayak Kini \& Basri, 2021a). Almost $46 \%$ of respondents were found to use Google Pay, $17 \%$ each were found to use Phonepe and PayTM followed by Yono (SBI), Imobile (ICICI), BHIM and the others (fig 2). Almost 55\% were males and 45\% females and half of this sample population were in the age group of 25-40 years (millennials) earning anywhere between $\$ 1-\$ 13,468$ per year (1 US\$ = Rs 74.25, 03 August 2021). The educational background of more than half of the sample (57\%) was found to be postgraduates (Table 1).

\section{Measurement model}

First, the lower-order constructs were taken into consideration and reliability and validity of the constructs were calculated for the reflective measurement models (refer to Table 2) For reliability, Cronbach's alpha and composite

Table 1. Respondents' demographic and FinTech app usage profile.

\begin{tabular}{|c|c|c|c|}
\hline & & Counts & Percentage (\%) \\
\hline \multirow[t]{2}{*}{ Gender } & Male & 210 & 55 \\
\hline & Female & 170 & 45 \\
\hline \multirow[t]{4}{*}{ Age } & Below 25 & 116 & 31 \\
\hline & $25-40$ & 188 & 49 \\
\hline & $41-60$ & 69 & 18 \\
\hline & $60+$ & 7 & 2 \\
\hline \multirow[t]{4}{*}{ Educational qualification } & Undergraduate & 23 & 6 \\
\hline & Graduate & 91 & 24 \\
\hline & Post Graduate & 215 & 57 \\
\hline & Doctorate & 51 & 13 \\
\hline \multirow[t]{4}{*}{ Annual income } & Below 1 Lac & 86 & 23 \\
\hline & $1 \mathrm{Lac}-5 \mathrm{Lac}$ & 111 & 29 \\
\hline & 5 Lac - 10 Lac & 123 & 32 \\
\hline & Above 10 lac & 60 & 16 \\
\hline \multirow[t]{7}{*}{ Financial app used } & Google Pay & 175 & 46 \\
\hline & Phone Pe & 66 & 17 \\
\hline & РаyTM & 63 & 17 \\
\hline & SBI Yono & 29 & 8 \\
\hline & Imobile & 14 & 4 \\
\hline & BHIM/UPI & 12 & 3 \\
\hline & Others & 20 & 5 \\
\hline
\end{tabular}




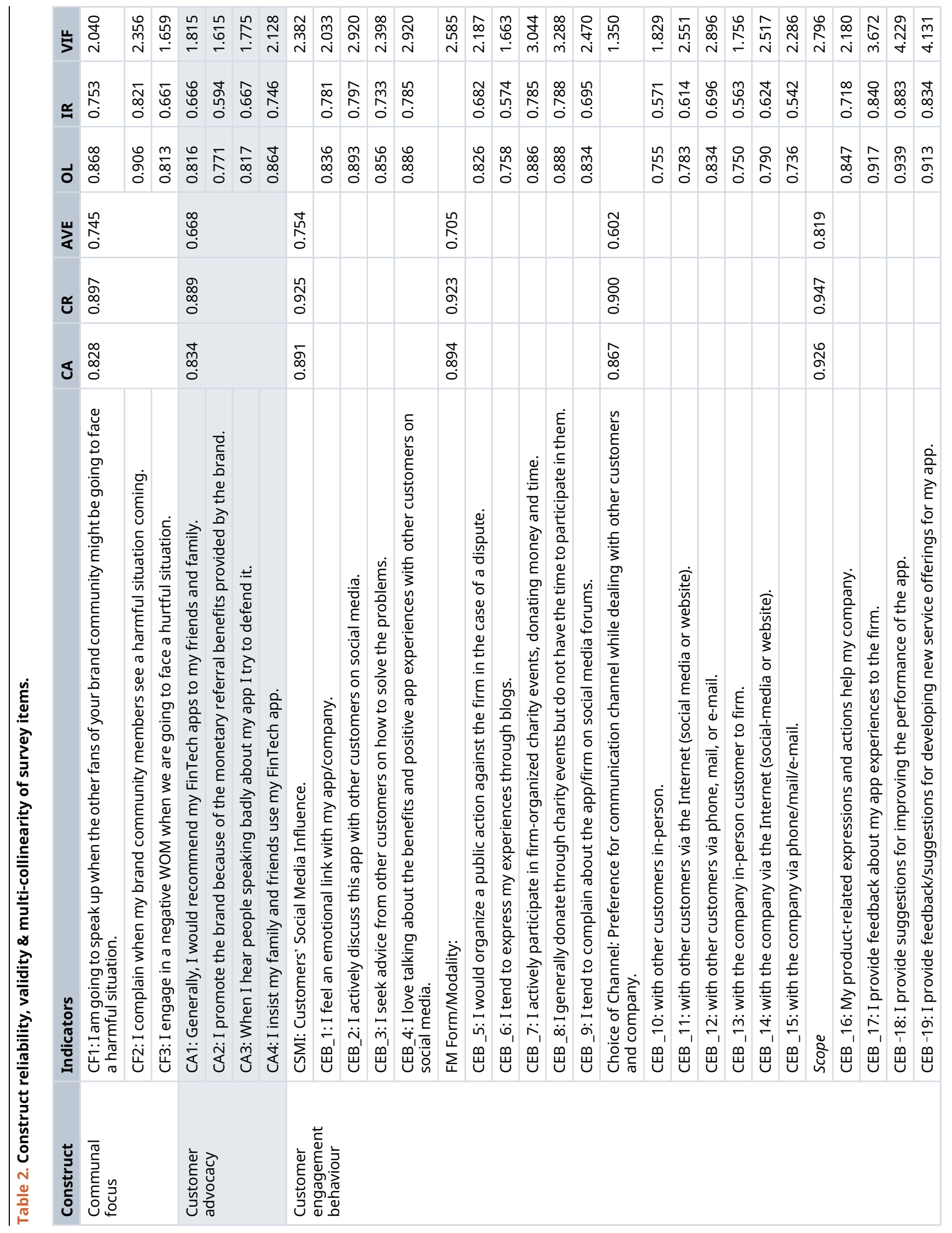




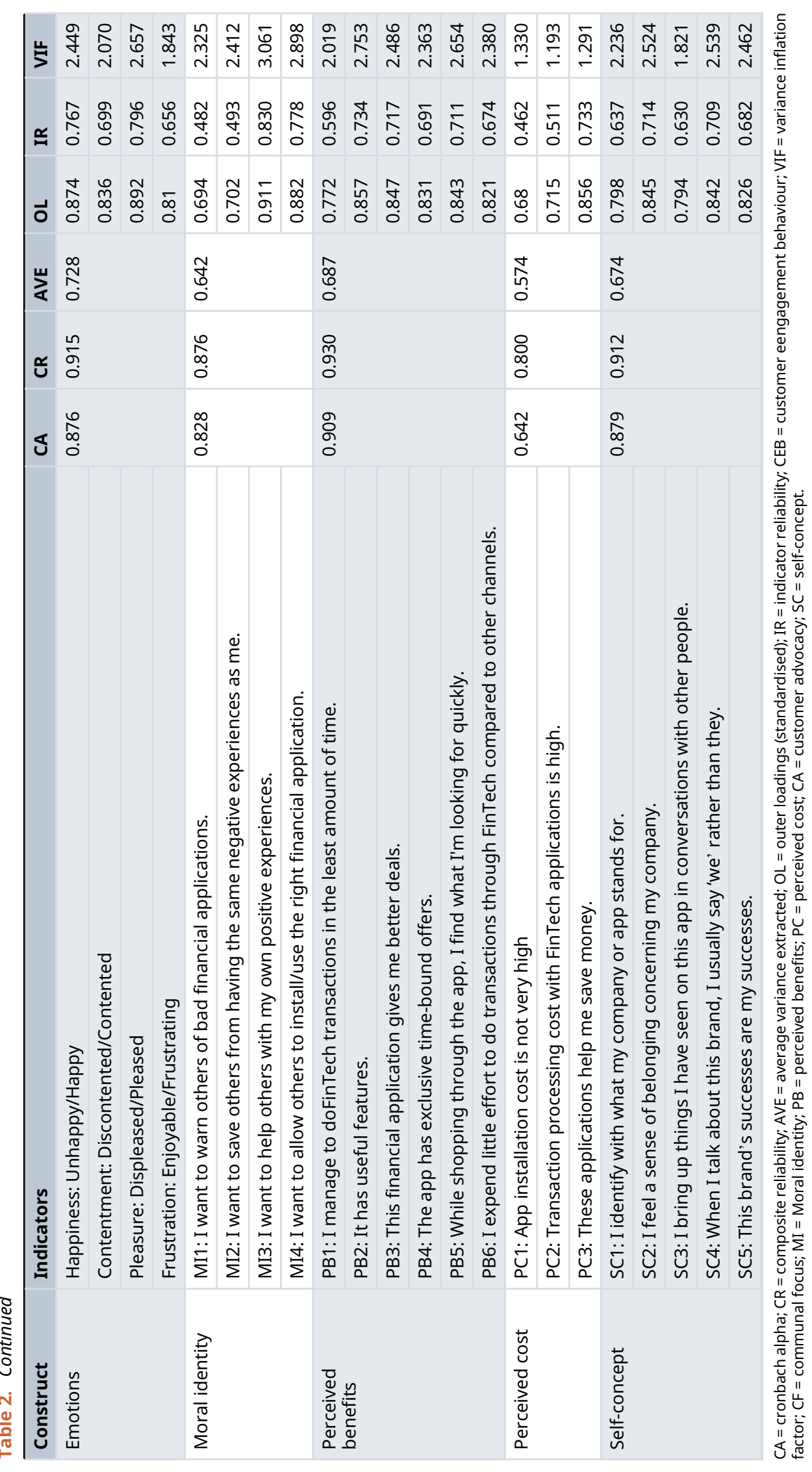


reliability were checked and for validity, convergent validity and discriminant validity were assessed. Cronbach's $\alpha$ value for each construct is well above the threshold limit of $\alpha \geq 0.70$ (Henson, 2001). Convergent validity was found to be acceptable as the average variance extracted (AVE) was greater than 0.5 . Indicator reliability for each indicator was observed to be 0.70 or higher and was found acceptable (Hulland, 1999). Discriminant validity was assessed by heterotrait-monotrait (HTMT) ratio of correlation (Henseler et al., 2015), with values below the threshold of 0.9 acceptable. Multi-collinearity of each construct was checked where variance inflation factor (VIF) values were found to be below 5 hence they are moderately correlated and are not evidenced to create any issue. The assessment of the measurement model substantiated that all the construct measures are reliable and valid.

The latent scores of the four lower-order constructs of CEB were added to the data set before running stage two. Here the four latent variable constructs acted as the indicators of the higher-order construct CEB. The measurement model of the formative higher-order construct (HOC) CEB was validated by running the bootstrapping procedure with 5000 samples. The outer weights were checked for significance, here the outer weight of FM (form/modality) was $<0.5$ and that of scope, CSMI and channel were below 0.5 , hence the outer loading was then checked which was $>0.5$ and was thus found to be significant.

\section{Structural model assessment}

The structural model was assessed using the principal measure of assessment which is the coefficient of determination $\mathrm{R}^{2}$ (Henseler et al., 2012). The high $\mathrm{R}^{2}$ value of 0.465 for customer engagement behaviour and 0.495 for customer advocacy signifies that almost $46.5 \%$ of the variance in CEB is explained by its antecedents which are emotions, self-concept, communal focus, perceived cost and benefits. Also, half of the variance in customer advocacy is explained by CEB. The high $\mathrm{R}^{2}$ values thus substantiate the model's predictive validity. The model fit indices were checked. SRMR value is 0.068 which is $<0.10$ or 0.08 (Hu and Bentler, 1999) and NFI (normed fit index) of 0.668 represents an acceptable fit. RMS_theta is 0.104 which is well below the threshold value of 0.12 .

\section{Direct effects}

The direct and indirect effects of various constructs were analyzed. The path-coefficient ' $\beta$ ' of a path, its $t$ statistics, p-value, effect size $\mathrm{f}^{2}$ and whether hypotheses on direct paths are supported or not are outlined in Table 3 . In terms of variables having the highest influence on CEB suggested by path-coefficient, self-concept has the highest influence on $\operatorname{CEB}(\beta=0.366)$ followed by communal focus $(\beta=0.184)$, perceived benefits $(\beta=0.118)$ and emotions $(\beta=0.110)$. The $\mathrm{f}^{2}$ values signify the effect sizes of the path. The path self-concept> CEB has the highest $\mathrm{f}^{2}$ value 0.145 followed by communal focus $\left(f^{2}=0.095\right)$, perceived benefits $\left(f^{2}=0.023\right)$, suggesting a small effect and emotions with an $f^{2}$ value of 0.019 suggesting that there is no effect of emotions on CEB's $\mathrm{R}^{2}$.

CEB, communal focus and emotions are found to have a significant effect on customer advocacy as suggested by path coefficients $0.303,0.279$ and 0.198 respectively and the effect sizes $\mathrm{f}^{2}$ values of $0.098,0.095$ and 0.065 respectively.

Table 3. Direct effects and effect sizes $\left(\mathbf{f}^{2}\right)$ of customer predispositions and engagement on advocacy behaviours.

\begin{tabular}{|c|c|c|c|c|c|}
\hline Hypothesised path relationships & $\boldsymbol{\beta}$ & $\mathbf{t}$ & p & $f^{2}$ & Hypothesis \\
\hline H1: CEB -> customer advocacy & 0.303 & 5.032 & 0.000 & 0.098 & Supported \\
\hline H2: Emotions -> CEB & 0.110 & 2.225 & 0.026 & 0.019 & Supported \\
\hline H3: Emotions -> customer advocacy & 0.198 & 4.389 & 0.000 & 0.065 & Supported \\
\hline H4: Self-concept -> CEB & 0.366 & 6.625 & 0.000 & 0.145 & Supported \\
\hline H5: Self-concept -> customer advocacy & 0.101 & 1.719 & 0.086 & 0.010 & Not supported \\
\hline H6: Moral identity -> CEB & 0.007 & 0.149 & 0.881 & 0.000 & Not supported \\
\hline H7: Moral identity -> customer advocacy & -0.014 & 0.265 & 0.791 & 0.000 & Not supported \\
\hline H8: Communal focus -> CEB & 0.184 & 3.225 & 0.001 & 0.040 & Supported \\
\hline H9: Communal focus -> customer advocacy & 0.279 & 5.264 & 0.000 & 0.095 & Supported \\
\hline H10: Perceived cost -> CEB & 0.064 & 1.051 & 0.294 & 0.005 & Not supported \\
\hline H11: Perceived benefits -> CEB & 0.118 & 1.967 & 0.049 & 0.023 & Supported \\
\hline
\end{tabular}

$\mathrm{CEB}=$ customer engagement behaviour. 
Table 4. Indirect effects of customer predispositions on advocacy behaviours mediator being customer engagement behaviour (CEB).

\begin{tabular}{|l|l|l|l|l|}
\hline Path & Path coefficients & $\mathbf{t}$ & $\mathbf{p}$ & Significance \\
\hline Perceived cost -> CEB -> customer advocacy & 0.019 & 1.020 & 0.308 & Not significant \\
\hline Moral identity -> CEB -> customer advocacy & 0.002 & 0.115 & 0.908 & Not significant \\
\hline communal focus -> CEB -> customer advocacy & 0.056 & 2.506 & 0.012 & Significant \\
\hline Self-concept -> CEB -> customer advocacy & 0.111 & 4.115 & 0.000 & Significant \\
\hline Emotions -> CEB -> customer advocacy & 0.033 & 1.815 & 0.070 & Not significant \\
\hline Perceived benefits -> CEB -> customer advocacy & 0.052 & 2.230 & 0.026 & Significant \\
\hline
\end{tabular}

Again, based on the $t$ and p-value, moral identity has an insignificant effect both on CEB and customer advocacy whereas perceived cost has an insignificant effect on CEB.

Indirect effects

The mediator CEB necessitates the need for checking the significance of indirect effects for the model. The indirect effect of self-concept on customer advocacy is the highest, followed by the communal focus and perceived benefits as suggested by the $t$ and the $p$ values as well as the path coefficients in Table 4 . However, there is no significant indirect influence of perceived cost, moral identity or emotions on customer advocacy.

\section{Mediation effects}

Customer engagement behaviour fully mediates the relationship between self-concept and customer advocacy (CA) as the direct relation between them is insignificant whereas the indirect relation is significant. CEB partially mediates the path between perceived benefits and CA with a VAF (variance accounted for) $=0.306(30.6 \%)$, the path communal focus and $\mathrm{CA}$ with $\mathrm{VAF}=0.166(16.6 \%)$. CEB does not mediate the other paths such as emotions $->\mathrm{CA}$, perceived cost $->\mathrm{CA}$ or moral identity $->$ customer advocacy.

\section{Discussion}

In the FinTech industry, the extensive usage of innovative technology has drastically reduced the direct face-to-face customer communications requiring experiential elements to be cherished. Our study result empirically suggests that CEBs displayed by e-WOM (e-word of mouth) behaviour are predominantly experiential and result in non-transactional outcomes such as advocacy. Study results show self-concept has a direct effect on CEB supporting the Levy and Hino (2016) study which encourages social media conversations based on a sense of brand belongingness. Self-concept also shows an indirect effect on advocacy that is fully mediated by CEB. This means that customers with a positive selfconcept associated with the product tend to advocate the product only if they are engaged positively. Thus, managers need to focus on identifying and nurturing the self-concept of their customers where customers identify themselves with the brand, for them to engage. This can be achieved by having individual 'thought leaders' whose opinions on products are followed by the customers to make buying or usage decisions. Customers' product benefit perceptions can engage customers positively but cost perceptions of the FinTech transaction do not inspire them to propagate any e-WOM to their brand community.

The study results show that the emotional dimension of engagement has a direct positive effect on both engagement and advocacy (e-WOM). If emotions are positive, customers tend to experience a positive CEB or recommend the product to other customers in their social media community thus being favourable to the company, validating the previous studies by Garg (2005) and Levy and Hino (2016). If emotions are negative customers end up with negatively valenced CEB making customers less likely to recommend products. This also confirms previous studies on negative emotions linked to disengagement (van Doorn et al., 2010). Study results suggest customers' propensity to help others does not result in e-WOM or a referral campaign refuting previous studies by Sundaram (1998) and van Doorn et al. (2010).

Our study propositions companies to design and build the products and applications to address customer needs. Companies now need to invest in creating unique engaging experiences accommodating customers' perceptions on product benefits, their inherent communal focus, self-concept and emotional needs in mind for them to engage and promote the brand to others turning them into advocates. FinTech firms need to primarily have platforms and social media channels that nurtures $\mathrm{C} 2 \mathrm{C}$ interactions, reviews, and testimonials favourable for the FinTech brands and companies. The companies can inspire improved perceptions on product benefits by implementing necessary mechanisms that make the 
transactions safer, faster, smoother, and more convenient. In addition, FinTech companies should incorporate innovative features, deals and offers customised to the past app user behaviour and the market needs. Moreover, it becomes essential not to hurt the communal feelings of the product community giving way to any unfavourable CEB such as a negative WOM. This implies that brands need to be focused and sensitive to the needs of community groups, which otherwise can turn into a negative engagement affecting a larger customer base.

This empirical study authenticates the role of CEB as a mediator fully mediating the relationship path self-concept $->$ customer advocacy and partially mediating the relationship paths perceived benefits $->$ customer advocacy and communal focus -> customer advocacy. Correspondingly, it assists practitioners to devise suitable and personalised segmentation or promotional strategies for various marketing campaigns.

\section{Practical implications}

This paper provides directions for marketing managers, e-marketers, technologists, academicians, and practitioners of engagement marketing in the FinTech industry. It guides the managers on how best to engage customers through self-concept, emotional connect and by suitably managing customer predispositions so that they display positive advocacy behaviours (reviews/testimonials). These insights may help the firms to enhance personalization and digital engagement in real-time and improve customer experience by responding to customer needs through co-created offerings. The knowledge of the factors which motivate customers to engage or disengage and prevailing customers' level of engagement/disengagement may help in designing a robust classification and segmentation strategy. Hence, this study principally assists FinTech managers on the ways to devise and implement the right marketing strategy based on various customer needs leading to continued advocacy behaviours.

\section{Research limitations and future research agenda}

The data collected for this quantitative study was from the financial app users of the southern region of India alone, hence it may limit the external validity of its results. The respondents used an online form to share their responses during lockdown causing a biased response due to COVID-19. Also, since the study was purely quantitative, it would have failed to capture other dynamic and subjective ideas of engagement behaviour in this ever-evolving, emerging FinTech industry which would have been possible with a mixed-method approach involving both quantitative and qualitative techniques.

The study could be simulated for other service industries such as e-commerce, healthcare, education, tourism, media and entertainment which dwell on non-transactional behaviours. As observed, there are different types of CEBs such as e-WOM, referrals, reviews, recommendations, testimonials, and blogging, with CEBs being specific to the particular industry. Correspondingly, paths of customer predispositions $>$ CEB $>$ customer advocacy in this model for the FinTech industry can be studied with certain demographic variables as the moderators. Similar to customer predispositions influencing engagement and advocacy behaviours, a positive recommendation and e-WOM could trigger positive emotions, communal focus, self-concept or cost/benefit perceptions and make the customer engage with the brand. This circular nature of relationships is a promising new area for future research. Studies with various population groups and cultures, for firm-based, and context-based factors apart from customer-based factors is also a great possibility. A qualitative approach to understanding CEBs for a specific industry or a population group may prove insightful. A longitudinal study of CEBs may be desirable as the customers' perceptions keep evolving with time as new products and technologies emerge. Moreover, future studies could also explore these $\mathrm{C} 2 \mathrm{C}$ interactions in different product or market settings where the nature of the precursors to customer advocacy may be altered.

\section{Conclusion}

It is observed that the emerging financial services companies are continuing to digitise and technologically disrupt. Especially, during the COVID-19 pandemic, as the adoption of technology-enabled contactless financial services rises, it becomes vital to meet the increasing customer expectations by assisting them in making correct choices and accomplishing customer goals. Apart from that, firms need to individualise, engage, and personalise the offerings to stand out in the ever-growing competition. The study results indicate that a highly pre-dispositional customer possessing a high selfconcept reciprocate positive e-WOM only when they are engaged with the financial application created through online influencer strategies. The positive CEBs get formed through self-concept, communal focus, emotions and perceived benefits related to the product helping to build advocacy behaviours. Results also indicate that emotions alone can directly influence advocacy for the FinTech industry. Thus, the emerging and competitive FinTech industry survives only if the emotionally connected customers, whose self-concept, communal focus and perceptions on product benefits are aligned with that of the companies demonstrating long-term brand engagement advocacy behaviours. 
Data availability

Underlying data

Mendeley Data: Raw data CSV processed for use in smartPLS-Fintech India-customer predispositions-engagementadvocacy behaviour. https://doi.org/10.17632/5j6csksgb4.5 (Nayak Kini \& Basri, 2021a).

Extended data

Mendeley Data: Survey form - Fintech India Customer predispositions-Engagement-Advocacy. https://doi.org/10.17632/ dfxjk69h8m.4 (Nayak Kini \& Basri, 2021b).

Mendeley Data: Information sheet and written consent form - FinTech India. https://doi.org/10.17632/njz464h8f8.1 (Nayak Kini \& Basri, 2021c).

Data are available under the terms of the Creative Commons Attribution 4.0 International license (CC-BY 4.0).

\section{References}

Anderson EW, Fornell C, Mazvancheryl SK: Customer satisfaction and shareholder value. J. Mark. 2004; 68(4): 172-185.

Publisher Full Text

Bagozzi RP, Gopinath M, Nyer PU: The role of emotions in marketing J. Acad. Mark. Sci. 1999; 27(2): 184-206.

Publisher Full Text

Bhat SA, Darzi MA: Customer relationship management. Int. J. Bank Mark. 2016; 34(3): 388-410.

Publisher Full Text

Blau PM: Justice in Social Exchange. Sociol. Inq. 1964; 34: 193-206. Publisher Full Text

Cerny CA, Kaiser HF: A study of a measure of sampling adequacy for factor-analytic correlation matrices. Multivar. Behav. Res. 1977; 12(1):

43-47.

PubMed Abstract | Publisher Full Text

Constantinides E, Fountain SJ: Web 2.0: Conceptual foundations and marketing issues. J. Direct Data Digit. Mark. Pract. 2008; 9(3): 231-244. Publisher Full Text

Cyrill M: Future of Fintech in India - Opportunities and Challenges, India Briefing. 2018, November 27.

Reference Source

Ernst \& Young: EY FinTech Adoption Index- The rapid emergence of FinTech. 2017.

Reference Source

Fullerton G: Creating advocates: The roles of satisfaction, trust and commitment. J. Retail. Consum. Serv. 2011; 18(1): 92-100.

Publisher Full Text

Feyen E, Frost J, Gambacorta L, et al.: BIS Papers No 117 Fintech and the digital transformation of financial services: implications for market structure and public policy. 2021.

Reference Source

Garg N, Inman J, Mittal V: Incidental and task-related affect: a re-inquiry and extension of the influence of affect on choice.

J. Consum. Res. 2005; 32(1): 154-159.

Publisher Full Text

Glavee-Geo R, Shaikh AA, Karjaluoto $\mathrm{H}$, et al.: Drivers and outcomes of consumer engagement. Int. J. Bank Mark. 2019; 38(1): 1-20.

Publisher Full Text

Grisaffe DB, Nguyen HP: Antecedents of emotional attachment to brands. J. Bus. Res. 2011; 64(10): 1052-1059.

Publisher Full Text

Hair JF, Hult GTM, Ringle CM, et al:: A Primer on Partial Least Squares Structural Equation Modeling (PLS-SEM). Thousand Oaks: Sage; 2013.

Han X, Kwortnik RJ Jr, Wang C: Service loyalty: An integrative model and examination across service contexts. J. Serv. Res. 2008; 11(1): 22-42.

Hayashi F, Bradford T: Mobile payments: Merchants' perspectives. Econ. Rev. 2014; 99: 5-30.

HeX, Inman JJ, Mittal V: Gender jeopardy in financial risk taking. J. Mark. Res. 2008; 45(4): 414-424.

Publisher Full Text
Hennig-Thurau T, Gwinner KP, Walsh G, et al.: Electronic word-of-mouth via consumer-opinion platforms: what motivates consumers to articulate themselves on the internet?. J. Interact. Mark. 2004; 18(1):

38-52.

Publisher Full Text

Henseler J, Ringle CM, Sarstedt M: Using partial least squares path modeling in advertising research: basic concepts and recent issues. Handbook of research on international advertising. 2012; 252.

Publisher Full Text

Henseler J, Ringle CM, Sarstedt M: A new criterion for assessing discriminant validity in variance-based structural equation modelling. J. Acad. Mark. Sci. 2015; 43(01): 115-135.

Publisher Full Text

Henson RK: Understanding internal consistency reliability estimates: A conceptual primer on coefficient alpha. Meas. Eval. Couns. Dev. 2001 Oct 1; 34(3): 177-189.

Publisher Full Text

Hulland J: Use of partial least squares (PLS) in strategic management research: A review of four recent studies. Strateg. Manag. J. 1999; 20(2): 195-204.

Publisher Full Text

Jaakkola $\mathrm{E}$, Alexander M: The role of customer engagement behavior in value co-creation: a service system perspective. J. Serv. Res. 2014; 17(3): 247-261.

Publisher Full Text

Jayasimha KR, Billore A: I complain for your good? Re-examining consumer advocacy. J. Strateg. Mark. 2016; 24(5): 360-376.

Publisher Full Text

Kaiser HF: The application of electronic computers to factor analysis. Educ. Psychol. Meas. 1960; 20(1): 141-151.

Publisher Full Text

Kumar $\mathrm{V}$, Pansari A: Competitive advantage through engagement.

J. Mark. Res. 2016; 53(4): 497-514.

Publisher Full Text

Lee I, Shin YJ: Fintech: Ecosystem, business models, investment decisions, and challenges. Bus. Horiz. 2018; 61(1): 35-46.

Publisher Full Text

Levy S, Hino H: Emotional brand attachment: a factor in customerbank relationships. Int. J. Bank Mark. 2016; 34(2): 136-150.

Publisher Full Text

Martin D, O'neill M, Hubbard S, et al.: The role of emotion in explaining consumer satisfaction and future behavioural intention. J. Serv. Mark. 2008; 22(3): 224-236.

Publisher Full Text

Moliner-Tena MA, Monferrer-Tirado D, Estrada-Guillén M: Customer engagement, non-transactional behaviors and experience in services: A study in the bank sector. Int. J. Bank Mark. 2019; 37(3): 730-754.

Publisher Full Text

Moliner MÁ, Monferrer-Tirado D, Estrada-Guillén M: Consequences of customer engagement and customer self-brand connection. J. Serv. Mark. 2018; 32(4): 387-399.

Publisher Full Text 
Mention AL: The age of FinTech: Implications for research, policy and practice. The Journal of FinTech. 2021; 01(01): 2050002.

Publisher Full Text

Nayak Kini A, Basri S: Raw data CSV processed for use in smartPLSFintech India-customer predispositions-engagement-advocacy behaviour. Mendeley Data. 2021a; V5.

Publisher Full Text

Nayak Kini A, Basri S: Survey form - Fintech India Customer

predispositions-Engagement-Advocacy. Mendeley Data. 2021b; V4.

Publisher Full Text

Nayak Kini A, Basri S: Information sheet and written consent form -

FinTech India. Mendeley Data. 2021c; V1.

Publisher Full Text

Oliver RL: Whence Consumer Loyalty?. J. Mark. 1999; 63(Special Issue):

33-44.

Publisher Full Text

Payments Council of India: Empowering payments: Digital India on the path

of revolution. 2020

Reference Source
Podsakoff PM, Organ DW: Self-reports in organizational research: Problems and prospects. J. Manag. 1986; 12(4): 531-544.

RBI Bulletin: FinTech: The Force of Creative Disruption: RBI.

(Accessed 11 November, 2021).

Reference Source

Sashi CM: Customer engagement, buyer-seller relationships, and social media. Manag. Decis. 2012; 50(2): 253-272.

Publisher Full Text

Sundaram DS, Mitra K, Webster C: Word-of-mouth communications: A motivational analysis. ACR North American Advances. 1998; 25: 527-531.

van Doorn J, Lemon KN, Mittal V, et al.: Customer engagement behavior: theoretical foundations and research directions.J. Serv. Res. 2010; 13(5): 253-266.

Publisher Full Text

Wong A: The role of emotional satisfaction in service encounters. Managing Service Quality: An International Journal. 2004; 14(5): 365-376.

Publisher Full Tex 


\section{Open Peer Review}

\section{Current Peer Review Status:}

\section{Version 1}

Reviewer Report 06 May 2022

https://doi.org/10.5256/f1000research.78732.r135480

(C) 2022 Kumar P. This is an open access peer review report distributed under the terms of the Creative Commons Attribution License, which permits unrestricted use, distribution, and reproduction in any medium, provided the original work is properly cited.

\section{Prashant Kumar}

School of Management, Asian Institute of Technology, Pathumthani, Thailand

The paper is well written - it follows the structure of a standard journal article, starting with introduction, literature review, method, results and discussion. It explains the research gaps and discusses at the end how the study addressed the gaps. The analysis is extensive and results are well-presented.

Please address following comments:

Write hypotheses in cause and effect format e.g. emotions have a positive effect on CEB.

In measurement scales, write how many items each scale contained.

In sample size, include how many respondents were contacted and how many responded and thus what was the response rate.

Thank you.

Is the work clearly and accurately presented and does it cite the current literature? Yes

Is the study design appropriate and is the work technically sound?

Yes

Are sufficient details of methods and analysis provided to allow replication by others? Yes

If applicable, is the statistical analysis and its interpretation appropriate? Yes

Are all the source data underlying the results available to ensure full reproducibility? Yes 
Are the conclusions drawn adequately supported by the results?

Yes

Competing Interests: No competing interests were disclosed.

I confirm that I have read this submission and believe that I have an appropriate level of expertise to confirm that it is of an acceptable scientific standard, however I have significant reservations, as outlined above.

Author Response 19 May 2022

Archana Nayak Kini, Manipal Academy of Higher Education, Manipal, India

Thank you for your review comments. Please find my point by point responses below.

Q1. Write hypotheses in cause and effect format e.g. emotions have a positive effect on CEB.

Answer: This has been revised as per suggestions and has been incorporated in the version 2 of the paper

$\mathrm{H} 1$ : There is a relationship between customer engagement behaviour (CEB) and customer advocacy.

Changed to

H1: Customer engagement behaviour positively impacts customer advocacy.

$\mathrm{H} 2$ : There is a relationship between emotions and CEB.

Changed to

H2: Emotions have a positive effect on CEB

H3: There is a relationship between emotions and customer advocacy.

Changed to

H3: Emotions have a positive influence on customer advocacy.

$\mathrm{H} 4$ : There is a relationship between self-concept and CEB

Changed to

H4: Self-concept impacts CEB positively.

H5: There is a relationship between self-concept and customer advocacy.

Changed to

H5: Self-concept impacts customer advocacy positively.

H6: There is a relationship between moral identity and CEB.

Changed to

H6: Moral Identity influences CEB in a positive manner.

H7: There is a relationship between moral identity and customer advocacy. 
Changed to

H7: Moral Identity inspires customer advocacy in a positive manner.

H8: There is a relationship between communal focus and CEB.

Changed to

H8: Presence of communal focus is positively associated with CEB.

H9: There is a relationship between communal focus and customer advocacy.

Changed to

H9: Customer advocacy responds positively to moral identity.

$\mathrm{H} 10$ : There is a relationship between perceived cost and CEB.

Changed to

H10: CEB is positively influenced by perceived cost.

$\mathrm{H} 11$ : There is a relationship between perceived benefits and CEB.

Changed to

H11: CEB is positively motivated by perceived benefits.

Q2: In measurement scales, write how many items each scale contained.

Answer: The survey questionnaire used a 5-point Likert scale adapted from several researchers such as Levy and Hino (2016) to capture customers' overall perceptions about self-concept having 5 items, van Doorn et al. (2010) for communal focus with 3 items, Hennig-Thurau et al. (2004) for moral identity having 4 items, Hayashi and Bradford (2014) for perceived cost having 3 items, perceived benefits having 6 items and Moliner et $a$. (2018), Kumar and Pansari (2016), for CEBs having 18 items, and Moliner et al. (2018) and Han et al. (2008) for advocacy concerning the specific apps they were using and having 5 items. For emotions, a 7-point Likert scale having 4 items which was adapted from Wong (2004) was used. The survey can be found as Extended data (Nayak Kini \& Basri, 2021 b ).

The number of items have been updated in the version 2 of the paper as well.

Q3. In sample size, include how many respondents were contacted and how many responded and thus what was the response rate.

Answer: We contacted 450 respondents and 420 of them responded with a response to complete the survey. Thus the response rate was $(420 / 450) * 100=93 \%$

Response rate has been updated in the Methods>Data Collection section of the paper as well.

Competing Interests: No competing interests were disclosed. 
(C) 2022 Kumar $\mathbf{K} \mathbf{N}$. This is an open access peer review report distributed under the terms of the Creative Commons Attribution License, which permits unrestricted use, distribution, and reproduction in any medium, provided the original work is properly cited.

\section{Naveen Kumar K iD}

National Institute of Bank Management, Pune, Maharashtra, India

While the number of FinTechs in India is on the rise to tap business opportunities emerging from the Covid-19 pandemic, the task before them is how to become friendlier to customers. In this regard, the paper aims at empirically testing the influence of customer-based antecedents such as emotions, moral identity, self-respect, customer focus, perceived cost, and product benefits for marketing. The paper considers major FinTechs operating in Karnataka State and concludes based on analysis of responses to the structured questionnaire from 380 customers from the same region. The paper employs Structural Equation Modeling using Smart Partial Least Square 3.0 to test the hypotheses. Results discussed in the paper are quite interesting, logically convincing, and practically oriented. Based on the study results, antecedents statistically found significant for engagement of customers include product benefits perception, self-respect, emotional contact, and customer predispositions.

\section{Q1. Is the work clearly and accurately presented and does it cite the current literature?}

Yes, the research findings are clearly and accurately discussed in the paper. The author deserves appreciation in mentioning a large number of earlier studies on the related aspects of the subject and setting the hypotheses in continuation of findings of the same. Among the customerbased antecedents mentioned in the paper, it is suggested to examine the relationship between safety \& security on one hand and customer advocacy on the other, based on the responses received from the respondents. This suggestion is made, taking into account the increasing number of frauds in online financial dealings in India. To elaborate, the share of suspected digital fraud attempts against financial services businesses increased by 89 percent during January-May, 2021.Therefore, the author is suggested to mention the importance of safety in FinTech dealings in the paper, which would be one of the considerations of customers. To know more about the current concerns relating to frauds in FinTech business, the author may go through these references: $1,2,3,4$

\section{Q2. Is the study design appropriate and is the work technically sound?}

Yes, the study design seems to be appropriate and the work technology is also sound. One more consideration should be made regarding the sample design. Currently, digital payment is limited largely to the population in urban and metro areas. Therefore, there is a felt need to increase the penetration of FinTech to the vast sections of the population which is unbanked and lacks a smartphone. Towards this end, the author may discuss the location of 380 respondents into Metro and Urban and Semi-urban and Rural and analyse responses accordingly. Quite likely, expectations of the customers from FinTech shall vary from one area to another.

\section{Q3. Are sufficient details of methods and analysis provided to allow replication by others?}

Yes. But, it is suggested to mention the following aspects in the paper:: 


\section{Major contents of the questionnaire}

2. Regarding the selection of FinTechs, the Payment Banks are not considered. But, this bank has now more than 5 crores customers. Therefore, the reason for not including the same should be stated.

3. Details of the profession of the respondents in the sample should be shared in the paper, since the use of FinTech varies from fixed income group users to business income group users.

\section{Q4. If applicable, is the statistical analysis and its interpretation appropriate?}

Statistical analysis and interpretation are very much appropriate and impressive. Statistical tools/tests are also in line with the earlier studies referred to in the paper. Two suggestions are made relating to analysis and interpretation:

The significance of each statistical tool/test stated in the paper shold be explained in simple terms for the benefit of the readers and,

The paper should state whether it attempts to make any change in the statistical tools as employed in the earlier studies.

Q5. Are all the source data underlying the results available to ensure full reproducibility?

Yes. Future work may be looked into the interaction between primary and secondary analysis.

Q6. Are the conclusions drawn adequately supported by the results?

The author deserves full appreciation for carrying out the extensive statistical analysis to test the hypotheses. The results of the analysis are almost in line with the earlier studies. Findings of the study make a significant contribution to the existing fund of knowledge.

\section{References}

1. Mor N: Committee on Comprehensive Financial Services for Small Businesses and Low Income Households. Reserve Bank of India. 2013. Reference Source

2. Gandhi SR: FinTechs and Virtual Currency. FinTech Conference 2017. 2017. Reference Source

3. Rabi Sankar ST: Responsible Digital Innovation. Global Fintech Festival. 2021. Reference Source

4. Consultation Paper on Peer to Peer Lending. Reserve Bank of India. 2016. Reference Source

Is the work clearly and accurately presented and does it cite the current literature? Yes

Is the study design appropriate and is the work technically sound? Yes

Are sufficient details of methods and analysis provided to allow replication by others? Yes

If applicable, is the statistical analysis and its interpretation appropriate? 
Yes

Are all the source data underlying the results available to ensure full reproducibility? Yes

Are the conclusions drawn adequately supported by the results?

Yes

Competing Interests: No competing interests were disclosed.

I confirm that I have read this submission and believe that I have an appropriate level of expertise to confirm that it is of an acceptable scientific standard.

Author Response 19 May 2022

Archana Nayak Kini, Manipal Academy of Higher Education, Manipal, India

Q1. Is the work clearly and accurately presented and does it cite the current literature?

Yes, the research findings are clearly and accurately discussed in the paper. The author deserves appreciation in mentioning a large number of earlier studies on the related aspects of the subject and setting the hypotheses in continuation of findings of the same. Among the customer-based antecedents mentioned in the paper, it is suggested to examine the relationship between safety \& security on one hand and customer advocacy on the other, based on the responses received from the respondents. This suggestion is made, taking into account the increasing number of frauds in online financial dealings in India.

Q1 Answer:

The purview of our study is exclusively for a sample of customers who have adopted online payments using apps such as GooglePay, PhonePe, BHIM which is one of the broader offerings under FinTech. Other offerings include peer to peer lending, virtual currency such as cryptos and NFTs (non-fungible tokens), insurance as mentioned in the articles 1, 2, 3, 4 related to the online frauds in the FinTech industry. The security and fraud detection related to the online payments are already being managed using face recognition, AI (Artificial Intelligence) and ML (Machine Learning) (Tekkali \& Vijaya, 2021). The Fraud Detection System allows one to detect illegal actions and malicious behaviours and efforts before they cause major damage to the firm and customers (Gupta \& Jhamb, 2020; Samet, 2013). Online payments' system design, architecture, authentication mechanisms and algorithms being system level factors which manage the security and privacy requirements are extrinsic in nature and are not considered for this study. This exclusion has been included as a research limitation of the study.

The main focus thus is on the intrinsic factors of the customers such as emotions, their perceptions about product cost \& benefits, their moral identity, self-concept and communal focus. These factors were identified from literature as they were predominantly influencing customer engagement behaviours in the tech-enabled financial services (Van Doorn et al., 2010. CEB (Customer Engagement Behaviour) is a behavioural construct that is primarily non-transactional in nature and goes beyond purchases and financial transactions. It is proven that emotional and behavioural factors, rather than a simply transactional strategy, influence a bank's relationship with consumers, resulting in bank advocacy (Levy \& 
Hino, 2016; Bhat \& Darzi, 2016).

\section{Q2. Is the study design appropriate and is the work technically sound?}

Yes, the study design seems to be appropriate and the work technology is also sound. One more consideration should be made regarding the sample design. Currently, digital payment is limited largely to the population in urban and metro areas. Therefore, there is a felt need to increase the penetration of FinTech to the vast sections of the population which is unbanked and lacks a smartphone. Towards this end, the author may discuss the location of 380 respondents into Metro and Urban and Semi-urban and Rural and analyse responses accordingly. Quite likely, expectations of the customers from FinTech shall vary from one area to another.

\section{Q2 Answer:}

On examining the sample, it is observed that $38 \%$ of the population is from urban, $46 \%$ from semi-urban areas, about $11 \%$ from metros and only about $3 \%$ from rural areas. As the majority of the sample population i.e. $84 \%$ is in semi-urban and urban, data analysis of this paper also demonstrates the expectations and behaviours of these customers. Therefore, future studies can focus on rural areas.

The location of the sample is incorporated in the 'Results' section of the paper.

\section{Q3. Are sufficient details of methods and analysis provided to allow replication by others?}

Yes. But, it is suggested to mention the following aspects in the paper.

1. Major contents of the questionnaire -Q3 >1 >Answer: The survey questionnaire used a 5-point Likert scale adapted tools from several researchers such as Levy and Hino (2016) to capture customers' overall perceptions about self-concept having 5 items, van Doorn et al. (2010) for communal focus with 3 items, Hennig-Thurau et al. (2004) for moral identity having 4 items, Hayashi and Bradford (2014) for perceived cost having 3 items, perceived benefits having 6 items and Moliner et al. (2018), Kumar and Pansari (2016), for CEBs having 18 items, and Moliner et al. (2018) and Han et al. (2008) for advocacy concerning the specific apps they were using and having 5 items. For emotions, a 7-point Likert scale having 4 items which was adapted from Wong (2004) was used. The survey questionnaire can be found as 'Extended data' (Nayak Kini \& Basri, 2021 b).The number of items in the scale for each construct has been incorporated in the paper.

2. Regarding the selection of FinTechs, the Payment Banks are not considered. But, this bank has now more than 5 crores customers. Therefore, the reason for not including the same should be stated. Q3> 2> Answer: Payment banks (PB) are a model of banks introduced to achieve financial inclusion in a cashless economy back in 2015. They accept cash deposits from customers which is stored in digital wallets and used for payments and remittances, but they do not offer loans and credits unlike traditional banks. The services targeted migrant labour, low income households, farmers, small businesses and other users in mind. Unfortunately, lower adoption rate was observed in lower income groups due to lack of awareness, low level of trust and lesser perceived need for these services (Pramani \& Iyer, 2022). The PBs have 
continued to incur losses which have risen through 2017 till 2020 with the net consolidated loss as on March 2020 to be at INR 833 crores (RBI, 2020).

On the other hand, based on the various research reports, FinTech adoption rate has been constantly rising and it was the highest for India surpassing China (Ernst \& Young, 2021). Indian states such as Karnataka saw the highest rate of 26.64\%, followed by Maharashtra (15.92\%), and Delhi NCR (13\%) (Razorpay, 2020). In terms of digital payments, post COVID-19 disease outbreak, PhonePe, Googlepay, Policybazaar and other similar financial apps were extensively adopted and used contributing to an exponential trend unlike payment banks (RBI 2021). Hence the purview of the study included only these app-oriented behaviours which are non-transactional in nature.

3. Details of the profession of the respondents in the sample should be shared in the paper, since the use of FinTech varies from fixed income group users to business income group users.

Answer to Q3>3: The study considered majorly the fixed income group individuals with only about $7 \%$ of the sample population being business income users. The moderation analysis considering occupation as the moderator did not show any differences between these two groups of users. We have excluded the write-up on this analysis for brevity of the paper.

\section{Q4. If applicable, is the statistical analysis and its interpretation appropriate?}

Statistical analysis and interpretation are very much appropriate and impressive. Statistical tools/tests are also in line with the earlier studies referred to in the paper. Two suggestions are made relating to analysis and interpretation:

The significance of each statistical tool/test stated in the paper should be explained in simple terms for the benefit of the readers and,

The paper should state whether it attempts to make any change in the statistical tools as employed in the earlier studies.

Q4> 1> Answer: The sample was measured for sample adequacy using the KMO test and Bartlett's Test of Sphericity using IBM SPSS 26.0. Structural equation modelling (SEM) stating the path model and estimation of various quality parameters was analysed and reported using the Smart PLS 3.00 software, abiding by the latest guiding principles on Partial Least Squares (Hair et al., 2013; Henseler et al., 2012).

First, the measurement model was evaluated to check the reliability using cronbach's alpha and composite reliability. Cronbach's a value for each construct is well above the threshold limit of $a \geq 0.70$ (Henson, 2001). Indicator reliability for each indicator was observed to be 0.70 or higher and was found acceptable (Hulland, 1999).

For validity, convergent validity and discriminant validity were assessed. Convergent validity was found to be acceptable as the average variance extracted (AVE) was greater than 0.5 . Indicator reliability for each indicator was observed to be 0.70 or higher and was found acceptable (Hulland, 1999). Discriminant validity was assessed by heterotrait-monotrait (HTMT) ratio of correlation (Henseler et al., 2015), with values below the threshold of 0.9 acceptable.

Multi-collinearity of each construct was checked where variance inflation factor (VIF) values were found to be below 5 hence they are moderately correlated and are not evidenced to create any issue.

The structural model was assessed using the principal measure of assessment which is the 
coefficient of determination $\mathrm{R}^{2}$ (Henseler et al., 2012). The high $\mathrm{R}^{2}$ value of 0.465 for customer engagement behaviour and 0.495 for customer advocacy signifies that almost $46.5 \%$ of the variance in CEB is explained by its antecedents which are emotions, selfconcept, communal focus, perceived cost and benefits. The high $\mathrm{R}^{2}$ values substantiate the model's predictive validity.

The model fit indices were checked. SRMR value is 0.068 which is $<0.10$ or 0.08 ( $\mathrm{Hu}$ and Bentler, 1999) and NFI (normed fit index) of 0.668 represents an acceptable fit. RMS_theta is 0.104 which is well below the threshold value of 0.12 .

The hypotheses were tested by analysing the direct and indirect effects. The significance of the path was tested using the path co-efficient, p-value and t stats of the paths in the model. Similarly, the mediation effects and the level of partial mediation was measured using the VAF (Variance accounted for) value which is the amount of direct effect divided by the amount of the total effect (direct effect + indirect effect). The formula for VAF has been updated in the version 2 of the paper.

Q4> 2> Answer: The study does not attempt to make any change in the statistical tool but adapts the scales for different constructs from several researchers.

\section{Q5. Are all the source data underlying the results available to ensure full reproducibility?}

Yes. Future work may be looked into the interaction between primary and secondary analysis.

Answer to Q5: Sure, that can be one of the potential future studies.

\section{Q6. Are the conclusions drawn adequately supported by the results?}

The author deserves full appreciation for carrying out the extensive statistical analysis to test the hypotheses. The results of the analysis are almost in line with the earlier studies. The findings of the study make a significant contribution to the existing fund of knowledge.

\section{References}

Tekkali, C. G., \& Vijaya, J. (2021, August). A Survey: Methodologies used for Fraud Detection in Digital Transactions. In 2021 Second International Conference on Electronics and Sustainable Communication Systems (ICESC) (pp. 1758-1765). IEEE.

Samet, O. (2013). Introduction to online payments risk management. " O'Reilly Media, Inc.". Gupta, N., \& Jhamb, D. (2020). How India can develop its payments fraud prevention model: A study of emerging best practices. Journal of Payments Strategy \& Systems, 14(3), 237-255

Competing Interests: No competing interests were disclosed. 
The benefits of publishing with F1000Research:

- Your article is published within days, with no editorial bias

- You can publish traditional articles, null/negative results, case reports, data notes and more

- The peer review process is transparent and collaborative

- Your article is indexed in PubMed after passing peer review

- Dedicated customer support at every stage

For pre-submission enquiries, contact research@f1000.com 